\section{State of the Society}

The new year is the traditional time for assessments in all types of organizations. For the Materials Research Society, this has frequently been a time to ask where the Society has come from, and what does it want to be when it grows up. As incoming president, I see an exceptionally vibrant and dynamic society that I am extremely proud to represent. It remains a society where the individual volunteers are empowered, and one that increasingly has broad societal impact.

MRS has grown to over 13,000 members, becoming a large scientific society without the artery-hardening effects usually associated with such size. It has become international in scope, with over $35 \%$ of our members based outside the United States and strong international participation in the Meetings. And it continues to flourish technically. The core of MRS, our Meetings, remains exceptionally strong. The 2003 MRS Fall Meeting broke the all-time record for attendance and the 2004 Fall Meeting last November broke 2003's record in turn. The Meetings continue to capture exciting new technical areas very rapidly (e.g., the biomaterials / hybrid materials component of the Meeting that has grown steadily over the last five years). Fall '04 also showed exceptional innovations in the nontechnical component of the Meeting, with a close coupling to the MRS traveling science exhibition, Strange Matter, and a symposium (PP) for high-school teachers made an integral part of the Meeting.

In fact, across the board, the Society is addressing its nontechnical mission with increasing confidence. Strange Matter has become a hugely successful enterprise that other societies are starting to struggle to emulate. It has won numerous awards, most recently Scientific American's 2004 Science and Technology Web Site Award, and has turned into a springboard for MRS's outreach, becoming a fabulous asset in our efforts to broaden materials education and bring materials research to the general public. MRS is also increasingly active and visible in helping to set government research funding priorities within the United States, and we hope to broaden this impact in the coming years.

The role of the MRS President and the MRS Board of Directors in these successes is largely, quite frankly, to stay out of the way. The technical successes of the Meetings are a consequence of MRS's longstanding policy (unique among scientific societies) of selecting outstanding Meeting Chairs and empowering them to

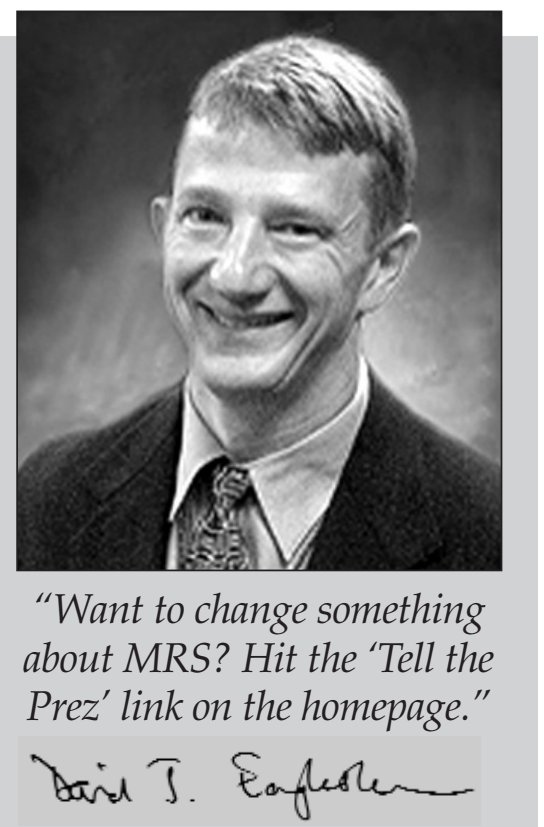

run their own best possible Meeting. The Meeting Chairs get to set the agenda, pick the technical topics, and choose or solicit symposia. They make decisions on items such as the plenary speaker, but also whether to run tutorials, and recognize achievements. The Meeting Chairs return the favor by, in turn, empowering their Symposium Organizers. This group drives the content and feel of their own piece of the Meeting. Because the Symposium Organizers get such free rein, the MRS Meetings attract exceptional and energetic scientific leaders who run their symposia in an equally anarchic fashion to the Meeting. Any member can propose a symposium, and historically, over 30\% of the symposia come from unsolicited proposals. For many members (including me), MRS gave us our first exposure to scientific leadership. This has led to MRS being a society where the technical agenda is set without vested interests that run a given technical area. This process has an admirable capability to bring up scientific leaders early in their careers and develop technical topics early in their development.

The success of the MRS Meetings is a direct consequence of allowing creative leadership from the rank and file of the membership. This rank-and-file empowerment extends beyond the Meetings. The MRS Bulletin is an excellent example and has an organic structure that mirrors the Meetings: The president chooses Volume Organizers, who have great freedom to pick topics and guest editors; the guest editors in turn define their issue and its technical slant, pick articles, and recruit the authors. The award-winning Strange Matter materials science exhibition for science museums began with a group of committed visionaries at the volunteer level, and at the beginning it had limited (and pretty hesitant) support from the formal "leadership" of the Society (including me). Historically, volunteer activists were responsible for the majority of MRS's new departures, including the formation of international MRS societies, the Bulletin, and University Chapters.

Several other initiatives this year reflect MRS's willingness to reinvent itself. It is revamping its print publications. It is redirecting its "government affairs" activity to work in a more proactive fashion with the funding decisions in the United States that affect over $60 \%$ of the membership. It is moving this year to aggressively overhaul its Web capabilities as the opportunity now exists for much broader electronic delivery of content (I note that MRS owns the first and second Google listings out of over 17 million hits returned from a search on "materials research").

Having been a 1996 member of the MRS Council (predecessor of the current Board) at a time when the Council of MRS was a distant oversight body for the highly engaged Executive Committee, I now find myself delighted to be a president during this time in the Society that is largely run by volunteer groups. You, the membership, are empowered by MRS as by no other society. Want to affect the Meeting content? Bring proposed symposium topics to future Meeting Chairs (www.mrs. org/meetings). Want to affect the Bulletin? Submit topics for special issues to the Volume Organizers or individual articles via the Web site (www.mrs.org/ publications/bulletin). Want to get involved in government affairs, interactions with other societies, public outreach, or other MRS activities? Hit the Committees page at www.mrs.org/geninfo/ committees/and volunteer for the relevant committee. Want to restructure the MRS

Web site, or arrange to have MRS deliver a personalized Materials Update just for you? Contact the Web Task Force. (Now is the perfect time, as this group is just starting to reshape E-benefits and services). Want to change something else about MRS? E-mail me at david_eaglesham@amat.com or hit the "Tell the Prez" link on the homepage.

It's your Society. Get involved!! DAVID J. EAGLESHAM 2005 MRS President 